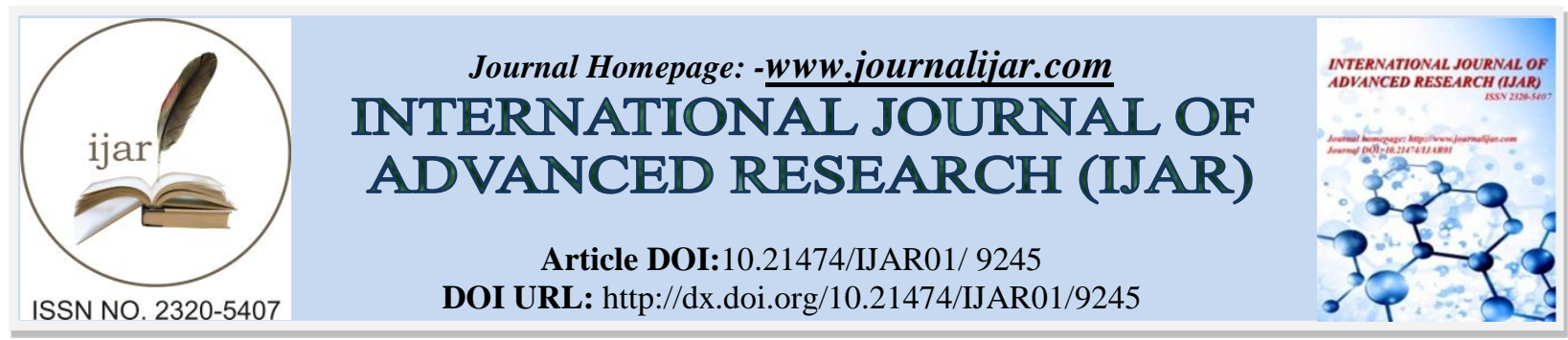

RESEARCH ARTICLE

\title{
STUDY OF SERUM ADIPONECTIN LEVEL IN IMPAIRED GLUCOSE TOLERANCE SUBJECTS.
}

Poonam Yadav ${ }^{1}$ and G.G. Kaushik
1. University of Health Sciences, Jaipur.

2. Senior Professor, Department of Biochemistry, J.L.N. Medical College, Ajmer (Rajasthan). Rajasthan University of Health Sciences, Jaipur.

\section{Manuscript Info}

\section{Manuscript History}

Received: 08 April 2019

Final Accepted: 10 May 2019

Published: June 2019

Key words:-

Adiponectin, IGT,, Diabetes.

\section{Abstract}

The aim of study was to measure serum level of adiponectin in impaired glucose tolerance subjects and compare with healthy control subjects. In this study 120 Impaired Glucose Tolerance and 120 healthy subjects (age and gender matched) were enrolled. Body Mass Index (BMI), Glucose, Glycosylated haemoglobin (HbA1c), Insulin and Adiponectin were assessed. Serum adiponectin levels were lower in impaired glucose tolerance subjects compared with healthy controls $(3.1 \pm 1.1 \mu \mathrm{g} / \mathrm{ml}$ vs $8.5 \pm 2.2 \mu \mathrm{g} / \mathrm{ml}$, respectively, $\mathrm{P}<0.0001)$.

Copy Right, IJAR, 2019,. All rights reserved.

\section{Introduction:-}

Diabetes Mellitus is one of the main threat to human health in the twenty- first century and therefore should be controlled and managed early to avoid its complication. Type 2 diabetes is preceded by a pre-diabetes (PD) is a dysmetabolic state of glucose level between diabetes mellitus and normal glucose tolerance. This asymptomatic phase may last for years, and about one third of individuals with pre-diabetes finally develop type 2 diabetes.

According to American Diabetes Association (2018), Impaired glucose tolerance (IGT) is defined as two-hour glucose levels of 140 to $199 \mathrm{mg}$ per $\mathrm{dL}$ ( 7.8 to $11.0 \mathrm{mmol} / \mathrm{L})$ on the $75 \mathrm{~g}$ oral glucose tolerance test. These glucose levels are above normal but below the level that is diagnostic prevention for diabetes.IGT is commonly associated with both obesity and disturbances in insulin secretion and/or insulin resistance. It is characterized by reduced peripheral insulin sensitivity, near normal hepatic insulin sensitivity, and progressive loss of beta cell function.

Adiponectin (APN) is the most abundant adipose tissue derived protein (V. Urbanavicius et al;2008). It is involved in regulating glucose levels as well as fatty acid breakdown (Y. Arita et al;1999). Adiponectin levels seems to be reduced prior to the development of type 2 diabetes, and administration of adiponectin has been accompanied by lower plasma glucose levels as well as increased insulin sensitivity (A.S. Lihn et al;2005).

Although there are many evidences linking insulin resistance, serum adiponectin and type 2 diabetes. Data about serum Adiponectin concentration in Impaired Glucose Tolerance is limited. Therefore, present study was undertaken to evaluate serum adiponectin levels in patients with IGT and to compare it with healthy controls.

\section{Materials \& Methods:-}

120 impaired glucose tolerance subjects were recruited in this study from the OPD of Department of Medicine, Jawahar Lal Nehru Medical College and Associated group of Hospitals, Ajmer. The subjects were considered as 
IGT based on the ADA guidelines (2018). Age and gender matched 120 healthy subjects without a family history of diabetes were also recruited in this study to serve as the controls.. On a prescheduled morning, the subjects were requested to arrive after overnight fast (at least 10 hour) to provide a fasting blood sample. After collecting fasting blood samples, the subjects were given $75 \mathrm{~g}$ of glucose dissolved in $250 \mathrm{ml}$ of water. The blood was drawn via venepuncture $2 \mathrm{~h}$ after glucose load. After 30 mints of collection, the blood sample was centrifuged for 10-15 mints at 3000rpm to obtain the serum.

BMI was determined following standard procedures. Glucose was measured using the glucose oxidase method, (HbA1c) glycosylated hemoglobin was measured by ion exchange resin method (Trivelli et al;1971), Insulin and serum Adiponectin were measured using an enzyme linked immunosorbent assay (ELISA) technique.

The quantitative variables were expressed as the Mean \pm SD (Standard deviation) median (range). The baseline characteristic between IGT and healthy subjects were assessed using student's t-test for continuous variables (as applicable). All P-values were based on a two sided test of statistical significance. Significance was accepted at the level of $\mathrm{p}<0.05$.

\section{Results And Observation:-}

In this study, 120 cases of impaired glucose tolerance were compared with 120 healthy controls.

Table 1:-Anthropometric parameters of IGT subjects \& Healthy controls

\begin{tabular}{|l|c|c|c|}
\hline \multicolumn{1}{|c|}{ Parameters } & $\begin{array}{c}\text { IGT Cases } \\
\text { (Mean } \pm \text { SD })\end{array}$ & $\begin{array}{c}\text { Healthy Controls } \\
\text { (Mean } \pm \text { SD })\end{array}$ & P-Value \\
\hline AGE $(\mathrm{yrs})$ & $40.18 \pm 2.8$ & $40.35 \pm 2.9$ & $0.644(\mathrm{NS})$ \\
\hline WEIGHT $(\mathrm{kg})$ & $79.99 \pm 3.05$ & $51.58 \pm 4.9$ & - \\
\hline HEIGHT $(\mathrm{cm})$ & $1.67 \pm 0.05$ & $1.55 \pm 4.39$ & - \\
\hline BMI $\left(\mathrm{kg} / \mathrm{m}^{2}\right)$ & $28.53 \pm 1.7$ & $21.34 \pm 1.5$ & $<0.001(\mathrm{HS})$ \\
\hline
\end{tabular}

Table 2:-Biochemical parameters of IGT subjects \& Healthy subjects

\begin{tabular}{|l|c|c|c|}
\hline \multicolumn{1}{|c|}{ Parameters } & $\begin{array}{c}\text { IGT Cases } \\
\text { (Mean } \pm \text { SD })\end{array}$ & $\begin{array}{c}\text { Healthy Controls } \\
\text { (Mean } \pm \text { SD ) }\end{array}$ & P-Value \\
\hline $\begin{array}{l}\text { Fasting Plasma Glucose } \\
(\mathrm{mg} / \mathrm{dl})\end{array}$ & $117.2 \pm 4.5$ & $87.4 \pm 11.4$ & $<0.0001(\mathrm{HS})$ \\
\hline HbAlc $(\%)$ & $6.4 \pm 0.4$ & $5.1 \pm 0.3$ & $<0.0001(\mathrm{HS})$ \\
\hline Serum Insulin $(\mu \mathrm{IU} / \mathrm{ml})$ & $11.9 \pm 3.1$ & $9.8 \pm 2.2$ & $<0.0001(\mathrm{HS})$ \\
\hline Serum Adiponectn $(\mu \mathrm{g} / \mathrm{ml})$ & $3.1 \pm 1.1$ & $8.5 \pm 2.2$ & $<0.0001(\mathrm{HS})$ \\
\hline
\end{tabular}

$\mathrm{P}$ value $<0.0001$ is considered highly significant while $\mathrm{p}<0.01$ is considered significant.

Basic anthropometric parameters of IGT subjects and healthy subjects are summarized in table-1. There was no significant difference between IGT subjects and healthy subjects regarding mean age (40.18 \pm 2.8 vs. $40.35 \pm 2.9$ yrs. ). BMI mean $\pm \mathrm{SD}$ in $\mathrm{kg} / \mathrm{m}^{2}$ in IGT and healthy subjects was $(2.53 \pm 1.7 \mathrm{vs} .21 .34 \pm 1.5)$ and it was highly significant. Biochemical parameters of IGT subjects and healthy subjects are presented in table-2. IGT subjects had lower adiponectin levels compared to healthy subjects $(3.1 \pm 1.1 \mathrm{vs} .8 .5 \pm 2.2 \mu \mathrm{g} / \mathrm{ml}, \mathrm{P}<0.0001)$. Serum glucose, insulin, HbA1c were significantly high in IGT subjects $(\mathrm{P}<0.0001)$.

\section{Discussion:-}

In the present study, IGT subjects have significantly lower levels of adiponectin as compared to healthy control subjects. Our findings are in agreement with R. Luo et al;2011, who found that adiponectin concentrations were significantly lower in IGT group than normal glucose tolerance group, suggesting a possible association between circulating adiponectin concentration and glucose tolerance. The results of this study support the theory that circulating adiponectin has anti-inflammatory and anti-insulin functions in humans. F. Otsuka et al;2007 also reported decrease in adiponectin levels in patients with IGT than NGT. Results of this study suggest that plasma levels of adiponectin are already decreased in patients with IGT before the onset of overt diabetes, and that adiponectin levels may be a useful marker for identifying patients at high risk for coronary artery disease over in 
non-diabetic subjects. Adiponectin levels are reduced in pre-diabetic condition to the same extent as in early type 2 diabetes.

\section{Limitations of Study}

Our sample size was relatively small.

\section{Acknowledgements:-}

NIL

\section{Conflicts Of Interest}

We have no competing interests.

\section{Funding}

NIL

\section{Conclusion:-}

From the present study it is concluded that serum adiponectin levels gets decreased prior to onset of diabetes at prediabetic stage. We considered that adipocytokines could be a valuable marker to predict the possibility of development of metabolic disorders accompanying glucometabolic abnormalities.

\section{References:-}

1. Arita $\mathrm{Y}$, Kihara S, Ouchi N : Paradoxical decrease adipose specific protein, adiponectin, in obesity. Biochem Biophys Res Commun. 1999;257:79-83.

2. American Diabetes Association. "Diagnosis \& classification of diabetes mellitus". Diabetes care.2018;41(suppl.1):S13-S27

3. Bluher M, Brennan AM, Kelesidis T : Total and high molecular weight adiponectin in relation to metabolic variables at baseline and in response to an exercise treatment program. Diabetes Care. 2007;30:280-5.

4. Fumiyuki Otsuka, Seigo Sugiyama, Sunao Kojima, Hidetomo Maruyoshi, Tohru Funahashi, Tomohiro Sakamoto, Michihiro Yoshimura, Kazuo Kimura, Satoshi Umemura, Hisao Ogawa : Hypoadiponectinemia is associated with Impaired Glucose Tolerance and Coronary Artery Disease in non-diabetic men. Circ J. 2007;71:1703-1709.

5. Karastegiou K, Mohammed Ali V : The autocrine and paracrine roles of adipokines. Mol. Cell Endocrinol. 2010;318(1-2):69-78.

6. R Luo, X Li, R Jiang, X Gao, Z Lu and W Hua : Serum Concentrations of Resistin and Adiponectin and their relationship to insulin resistance in subjects with impaired glucose tolerance. The Journal of International Medical Research. 2012;40:621-630

7. Urbanavicius, A. Abraitiene, D. Vitkus, R. Borovkiene, Z. A. Kucinskiene Adiponectin and insulin resistance in pre-diabetes and early type 2 diabetes mellitus. Gerontologija. 2008;9(1):7-14. 